\title{
DA UNIVERSALIZAÇÃO DO ENSINO FUNDAMENTAL AO DESAFIO DA QUALIDADE: UMA ANÁLISE HISTÓRICA*
}

\author{
Romualdo Portela de Oliveira
}

\begin{abstract}
RESUMO: Partindo de uma análise de dados referentes à matrícula no ensino fundamental e médio, o artigo argúi que a universalização do ensino fundamental, processo ainda não inteiramente concluído, representa mudança de qualidade na dinâmica das contradições educacionais no Brasil. Se, de um lado, é processo de amplo sentido democratizador, por meio do qual parcelas da população historicamente alijadas progridam no interior do sistema de ensino, por outro, faz com que os processos de diferenciação social e de exclusão mudem de qualidade e de lugar. Emerge daí a crescente importância do debate acerca da qualidade de ensino como componente do direito à educação.
\end{abstract}

Palavras-chave: Ensino fundamental. Democratização do acesso. Política educacional. Expansão do sistema educacional.

\section{FROM THE UNIVERSALIZATION OF TEACHING TO THE CHALLENGE OF QUALITY: A HISTORICAL ANALYSIS}

ABSTRACT: This paper analyzes data on school enrollment in the fundamental and medium education in Brazil. It argues that the universalization of fundamental education, which is not yet concluded, represents a quality change in the dynamics of the educational contradictions in Brazil. Although it is a democratization process, through which social historically excluded groups can progress within the educational system, it changes the place and quality of social differentiation and exclusion. A debate on educational quality

\footnotetext{
* Versão revista e condensada de parte da tese de livre docência do autor, apresentada à Faculdade de Educação da Universidade de São Paulo (USP), em 2006, sob o título Estado e política educacional: desafios do século XXI.

** Livre-docente em Educaçāo e professor da Faculdade de Educação da USP. E-mail: romualdo@usp.br
} 
Da universalização do ensino fundamental ao desafio da qualidade...

as a component of the right to education is thus more and more important.

Key words: Fundamental teaching. Democratization of the access. Educational policy. Educational system expansion

\section{Introdução}

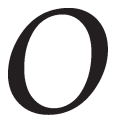

presente texto busca compreender a natureza das mudanças pelas quais passou a educação brasileira nos últimos anos, bem como o quadro geral que condiciona as políticas esboçadas para enfrentá-las.

Busca-se analisar a interação destas iniciativas com a dinâmica social, onde o peso e impacto das decisóes de governo são bem menores do que se é levado a supor se o foco da análise se torna a política governamental. Esta não tem o poder de determinar o social, ao contrário, interage com este na condição de coadjuvante, ainda que não desprezível. Exatamente por isso, a ação dos governos tem de se haver com limitações importantes.

No caso brasileiro, pode-se sumariar estas limitações em duas vertentes. De um lado, aquelas decorrentes das opções da política econômica que, salvo reorientação significativa, não mudam no próximo período. Foge ao escopo deste trabalho discuti-las. Importa ressaltar que algumas das mudanças necessárias na educação estão longe de serem viáveis sem turbulências consideráveis na área política e, particularmente, na econômica. Exemplo mais claro disso pode ser observado na necessária mudança do montante de recursos aplicados em educação. Esta é uma medida que impactaria as opçóes macroeconômicas e, portanto, a menos que sejam alteradas as opçôes nessa esfera, mas tal não se vislumbra nos padrões e montantes vigentes. Sequer aumentos "lentos e graduais", como os propostos no Plano Nacional de Educação (gasto de 7\% do Produto Interno Bruto), são exeqüíveis num futuro próximo. De outro, as limitações decorrentes da dinâmica do próprio sistema educacional, que, ao invés de "ser pautado", pauta a agenda dos governantes, condicionando sobremaneira o alcance dos "vôos" possíveis.

Sem desconhecer esses condicionantes, ao contrário, exatamente por eles, o que se busca aqui é analisar a dinâmica do sistema de ensino 
como primeiro passo para se compreender a natureza e o solo em que germinarão as reformas educacionais.

Ainda que não compartilhe com uma visão da política como o espaço da "possibilidade", é nesse terreno que nos encontramos ao discutir políticas públicas num dado Estado. As políticas setoriais são realizadas dentro das possibilidades e da lógica geral do status quo. A implantação de uma outra lógica requer outro Estado. Nesses termos, se nos colocamos apenas na perspectiva desse outro Estado, de maneira rígida, toda política setorial é equivocada, por ser insuficiente. É o que tenho chamado de "tática da limusine". Definido como padrão a noção de que todos devem ter uma limusine, qualquer política social será, de antemão, insuficiente e, portanto, passível de crítica, mas, mais ainda, inútil sua discussão. Em certa medida, nos deparamos aqui com um debate semelhante ao ocorrido no interior da II Internacional, quando os partidos social-democratas iniciaram seu processo de institucionalização, formulado na tentativa de se compreender os vínculos possíveis entre o "programa mínimo" e o "programa máximo". A opção da tática da limusine seria opor um ao outro.

Ainda que não veja alteraçôes substantivas no âmbito restrito da educação, é nessa esfera que estou concentrando minhas reflexões e, portanto, ainda que limitadas, é aí que vou procurar compreender a mudança. Pode-se, isso sim, tensionar os limites da política com a política educacional. É aí que coloco, por exemplo, a defesa por mais verbas para a educação.

Portanto, mesmo que os grandes embates sejam travados em outra esfera, ao se optar por analisar a política educacional, a amplitude da mudança é menos intensa e, portanto, requer um olhar mais atento. Ao concentrar o foco na dinâmica interna do sistema educacional, espero, com isso, perceber seus alcances e limites, seus avanços, fracassos e seus novos desafios. A menos que fortemente impulsionadas de fora da "cidadela educacional", da esfera social. O sistema educacional, em condiçóes normais, muda lentamente, mas muda.

Realizada esta pequena digressão de natureza metodológica, e contrariando o bom conselho que apregoa "não se dever declarar referencial teórico, mas praticá-lo”, é possível pontuar uma questão que encontra abundante repercussão na literatura brasileira sobre o tema: o entendimento de que nossa educação é "determinada" pela agenda 
Da universalização do ensino fundamental ao desafio da qualidade...

internacional, interpretando-se tal "determinação" como sendo impulsionada por organizações multilaterais, particularmente o Banco Mundial. Essa concepção, muitas vezes, é o "mirante" organizador da análise. O problema é que ela é prisioneira, de maneira estática, da "Teoria do Espelho", segundo a qual a educação seria um "reflexo" da correlação de forças vigente na sociedade e, portanto, mera reprodutora dos interesses dominantes. Neste caso, com o seguinte adendo, como a sociedade brasileira é dominada, os interesses transmitidos no terreno educacional seriam os desígnios do Império, do capital etc. De certa maneira, o problema desse enfoque é que, apesar de portador de uma forte retórica, seu "mirante" está postado em um ponto em que não vislumbra contradiçôes presentes no terreno educacional, ou as reduz a conflitos ideológicos. Daí a recorrente análise de documentos de organismos internacionais como expressão do que ocorre de fato.

Ainda que as reformas empreendidas ao longo dos anos de 1990, adentrando aos dias atuais, pautem-se por uma agenda mundializada, em cada país sua concretização se dá com diferenças, em ênfase e amplitude, decorrentes de história e trajetória específicas. Dessa forma, pela natureza e expressão da economia brasileira, ainda que as agências internacionais sejam um agente importante, longe estão de serem os determinantes dos resultados das políticas efetivamente implementadas. Luiz Antônio Cunha, em instigante ensaio (2002), chama a atenção para o fato de que muitas vezes as reformas empreendidas no Brasil são resultado de árduo conflito, público ou mesmo intramuros à burocracia educacional, mas não seguem uma dada "cartilha". Os organismos internacionais estão muito longe de ditar "as regras do jogo". Eles reforçam posiçóes, agentes e políticas já presentes no terreno nacional (Cunha, 1988).

Se tomarmos o sentido geral das reformas implantadas no Brasil nos últimos anos, elas não são nem a "receita das organizações internacionais" e nem a expressão pura das concepções neoliberais. A menos que interpretemos de uma forma tão ampla o neoliberalismo e a natureza das políticas aqui implementadas que, no limite, qualquer concepção seria neoliberal. Da priorização ao ensino fundamental à defesa de maior racionalização na gestão dos sistemas públicos de ensino, tudo seria expressão da vontade desse Deus ex machina. Ainda que, não custa repetir, as instituiçóes multilaterais e a concepção neoliberal de gestão 
do Estado sejam elementos importantes do debate, nem por isso o que temos é mera decorrência de implementação dessas concepçôes.

Outra coisa é a evidente hegemonia que o pensamento neoliberal (Moraes, 2000) logrou alcançar logo após a queda do muro de Berlim e a derrocada dos países do "socialismo real". Por isso, compreende-se porque muitos pesquisadores e estudiosos têm sobrevalorizado o papel dos organismos internacionais que propagam essa agenda. Segundo tal visão, estaríamos diante de uma agenda "induzida" (Dale, 2001).

Se a agenda internacional fosse a única ou mesmo a principal explicação dos processos de reforma pelos quais passa a maioria dos países, as respostas nacionais seriam idênticas ou muito semelhantes. Entretanto, as peculiaridades de cada formação social e as condições em que se efetiva a luta de classes e as expressões de seus conflitos na esfera educacional são elementos determinantes para se compreender que aspectos dessa agenda se viabilizam e que elementos permanecem como "programa" - no sentido de "dever ser". Muitas vezes, esse programa sequer é inteiramente absorvido pelos setores dominantes locais.

Apenas para citarmos um exemplo, mencionemos o ensino superior. Há mais de quatro décadas, a cobrança de anuidades em universidades públicas faz parte das recomendações das agências internacionais. No Brasil, caminhamos em sentido oposto. A Constituição de 1988 (CF/88) foi a primeira em nossa história, em nível federal, a estatuir o princípio da gratuidade nos estabelecimentos públicos, independentemente do nível de ensino. Ao mesmo tempo, em outros países, a cobrança de anuidades no ensino superior público foi implantada nos últimos anos. Destaquem-se, nesse caso, as experiências de Polônia, Chile e Colômbia, onde o processo de privatização acentuouse no último período.

Mesmo a peculiar (e ilegal!) interpretação dada ao inciso IV do artigo 206 da Constituição, que estabelece a gratuidade do ensino público nos estabelecimentos oficiais, restringindo-a a cursos regulares de graduação e pós-graduação, o que tem permitido a cobrança de todos os demais (extensão, aperfeiçoamento, especialização, MBAs etc.), é objeto de dura contestação, inclusive na esfera da justiça. ${ }^{1}$

O propósito deste trabalho, tomando como referência o movimento de expansão do ensino fundamental e médio, que supera histórico processo de exclusão, é explicitar as novas contradições e demandas 
Da universalização do ensino fundamental ao desafio da qualidade...

decorrentes desse processo, procurando, com isso, evidenciar o novo lócus e natureza da exclusão educacional.

Atribuo importância significativa à universalização do acesso ao ensino fundamental, posto que esta faz com que "as contradições mudem de lugar”, passando a concentrar-se na expansão das etapas posteriores a este e na qualidade da educação básica, notadamente do ensino fundamental.

Retomando-se a dinâmica histórica, nos últimos 80 anos, expandiram-se significativamente as oportunidades de acesso e permanência no sistema escolar para amplas camadas da população (Beisiegel, 1986), fazendo com que, ao final do século Xx, o ensino fundamental obrigatório estivesse praticamente universalizado no que diz respeito ao acesso. ${ }^{2}$ Ainda que com um atraso de quase um século em relação aos países desenvolvidos, esta expansão, de evidente característica democratizadora, confronta-se com uma perspectiva política de redução do investimento público em educação, decorrente das opções macroeconômicas do ajuste fiscal e da geração de superávits primários.

Tal tensão entre um sistema educativo em franca ampliação, por vagas e qualidade, e uma agenda política e econômica conservadora gera um conflito sem precedentes em nossa história educacional. Além do atendimento à demanda por mais educação, debatemos-nos com a tensão entre o direito à educação de qualidade para amplos contingentes da população ou sua negação, o que pode tornar inócua a democratização do acesso, quer seja por sua distribuição diferenciada, quer seja por, e também, relegar a qualidade a nichos de privilégio no interior do sistema educacional.

A seguir, analisa-se o acesso ao ensino fundamental, caracterizando-se os acúmulos das últimas décadas e identificando-se as contradiçóes e desafios que roubam a cena.

\section{A universalização do ensino fundamental}

Celso Beisiegel (1986, p. 383), em "Educação e sociedade no Brasil após 1930", afirma que

(...) a progressiva extensão das oportunidades de acesso à escola, em todos os níveis do ensino, para setores cada vez mais amplos da coletividade - ou, 
em outras palavras, o denominado processo de democratização do ensino - sem dúvida alguma aparece como o elemento central nas mudanças então observadas. Sob o impacto desta democratização das oportunidades, em poucas décadas, o antigo ensino criado e organizado para atender às necessidades de minorias privilegiadas vem sendo substituído por um novo sistema de ensino, relativamente aberto no plano formal e, pelo menos tendencialmente, acessível à maioria da população.

Com dados referentes ao início dos anos de 1970, publicado originalmente em 1984, decorridos mais de vinte anos, a tese central desse trabalho mantém-se essencialmente correta. Nesse período, intensificou-se a ampliação das oportunidades de escolarização para a população, praticamente se universalizou o acesso e a permanência no ensino fundamental e ampliaram-se significativamente os índices de conclusão. Segundo o Censo Escolar do INEP, em 2002, 2,78 milhões $^{3}$ de estudantes concluíram a oitava série, o que representa aproximadamente $80 \%$ da população na coorte etária. ${ }^{4}$

Tal processo gera uma demanda por expansão de todo o sistema, notadamente das etapas posteriores ao ensino fundamental. $\mathrm{O}$ ensino médio conheceu grande expansão nos últimos anos e o ensino superior vem crescendo de maneira significativa. Ao mesmo tempo, avulta a preocupação por qualidade no ensino fundamental, problema historicamente pouco visível diante dos mais evidentes e pungentes processos de exclusão gerados pelos altos índices de reprovação e evasão observados anteriormente.

Iniciemos apresentando a matrícula total no ensino fundamental. De acordo com dados de Anuários do IBGE, em 1965, as séries que hoje compõem o ensino fundamental possuíam 11,6 milhões de matrículas; em 1970 esse número passa para 15,9 milhões. Dessa forma, se considerarmos o período da ditadura militar (1965-1985), a matrícula cresceu $113,8 \%$, algo próximo a um crescimento médio de 3,9\% ao ano. No período subseqüente, 1985-1999, o crescimento total foi de $45,6 \%$, com uma média de 3,3\% ao ano. ${ }^{5}$ Ressalte-se, entretanto, que foi neste segundo período, por volta de 1990, que se atingiu $100 \%$ de matrícula bruta, ${ }^{6}$ alcançando, assim, a capacidade potencial de atendimento a todos na faixa etária.

Segundo os dados apresentados a seguir, os percentuais obtidos para matrícula líquida e bruta são apresentados na Tabela 1, segundo informações do INEP. 
Da universalização do ensino fundamental ao desafio da qualidade...

\section{Tabela 1}

(Taxa de Matrícula Bruta e Líquida no ensino fundamental: 1980-2003) ${ }^{7}$

\begin{tabular}{|c|c|c|}
\hline Ano & TMB & TML \\
\hline 1980 & 98 & 80 \\
\hline 1991 & 106 & 84 \\
\hline 1996 & 116 & 91 \\
\hline 2003 & 122 & 96 \\
\hline
\end{tabular}

Nesse período, o sistema educacional apresentou capacidade de absorver mais estudantes do que a população na faixa etária correspondente. Isso significa que, neste momento, temos mais alunos no ensino fundamental que a população na faixa etária correspondente. Assim sendo, a regularização do fluxo tende a ter impacto menor do que se o sistema ainda não tivesse capacidade instalada para atender a toda a faixa etária, vale dizer, as crianças estão na escola, mas atrasadas em seus estudos. Ao se regularizar a relação idade-série, não haveria, em princípio, necessidade de ampliar significativamente a rede física. Esse é um elemento importante para se pensar a futura expansão do atendimento, tanto do ensino médio, quanto do infantil e do profissional. ${ }^{8}$

Observe-se agora a matrícula total e a população na faixa etária correspondente, cujos dados são apresentados na Tabela 2, para o período 1975-2005.

No período de 1975 a 2002, a matrícula total ${ }^{9}$ no ensino fundamental no país cresceu 71,5\%, passando de 19,5 milhões para 33,5 milhões, tendo atingido a marca máxima de 36 milhões de matriculados em 1999. Segundo o IBGE, em 1975, a população de 7 a 14 anos era de 21,7 milhões e, em 2003 , de 28,3 milhões. A população desta faixa etária cresceu $24,4 \%$, aproximadamente um terço do crescimento do atendimento escolar. Isso indica que houve uma maior absorção das crianças e adolescentes nessa etapa da educação básica. Os dados do MEC/INEP revelam, também, uma TMB de 130\%, em 2002, e uma TML de $97 \%$.

Estes números evidenciam que, nessas últimas três décadas, praticamente universalizou-se o atendimento de toda a população 
no ensino fundamental. Além disso, durante a década de 1990, foi reincorporada parcela substantiva de alunos anteriormente excluídos ou que não haviam, ainda, ingressado no sistema escolar. Concomitantemente, ao final dos anos de 1990, ao cair a TMB no ensino fundamental, generaliza-se a melhoria dos índices de conclusão, observados primeiramente nos estados do Sudeste, notadamente em São Paulo e Minas Gerais. Isso significa que, além de reincorporarem-se setores anteriormente excluídos da escola ou com início tardio do processo de escolarização, as taxas de sucesso no ensino fundamental cresceram visivelmente.

\section{Tabela 2}

(Brasil. Ensino fundamental regular - Matrícula inicial: 1975-2005)

\begin{tabular}{|l|l|r|r|r|}
\hline Ano & Matrícula & $\mathbf{1 9 7 5 = 1 0 0}$ & Pop. 7-14 anos & TMB (\%) \\
\hline 1975 & 19.549 .249 & 100,0 & $*$ & \\
\hline 1980 & 22.598 .254 & 115,6 & 22.981 .805 & 98 \\
\hline 1985 & 24.769 .359 & 126,7 & 24.251 .162 & 102 \\
\hline 1989 & 27.557 .542 & 141,0 & 27.509 .374 & 100 \\
\hline 1994 & 32.132 .736 & 164,4 & 28.931 .666 & 111 \\
\hline 1996 & 33.131 .270 & 169,5 & 28.525 .815 & 116 \\
\hline 1999 & 36.059 .742 & 184,5 & 25.105 .782 & 143 \\
\hline 2000 & 35.717 .948 & 182,7 & 27.124 .709 & 131 \\
\hline 2003 & 34.438 .749 & 176,2 & 28.262 .461 & 122 \\
\hline 2004 & 34.021 .245 & 174,0 & & \\
\hline 2005 & 33.530 .007 & 171,5 & & \\
\hline
\end{tabular}

* Informaçōes não localizadas.

Apesar da necessidade de ainda se incorporar ao sistema educacional, em 2002, aproximadamente 3\% da população na faixa etária de 7-14 anos de idade (algo em torno de 800 mil crianças ${ }^{10}$ ), é interessante observar que, desde o final da década de 1980, quantitativamente, havia vagas no ensino fundamental para toda a população na faixa etária. A rede física já comportava toda a população escolarizável, entretanto, a entrada tardia na escola ou as múltiplas reprovações faziam com que alunos que deveriam estar mais adiantados em seus estudos 
Da universalização do ensino fundamental ao desafio da qualidade...

ocupassem, ainda, os bancos escolares em séries anteriores às adequadas. Dada a situação atual, com a oferta de 18\% de vagas (aproximadamente seis milhôes de estudantes) a mais do que a população na faixa etária, ao se regularizar o fluxo (entrada = saída com sucesso) haverá capacidade adicional de absorção de alunos em outras etapas da educação básica. Isso se aplica tanto ao ensino médio, quanto à educação infantil, ainda que nesse caso com mais necessidade de adaptações da rede física e que essa "poupança" de vagas não seja suficiente para cobrir o déficit potencial da educação infantil. No caso do ensino médio, provavelmente serão suficientes para absorver o crescimento próximo.

Ainda assim, apesar de já se oferecer mais vagas no ensino fundamental do que a população de 7 a 14 anos, é possível que, ao se concluir o processo de regularização do fluxo escolar e incorporarem-se os contingentes hoje excluídos, mantidas as atuais condiçôes de atendimento (número de horas-aula por dia, número médio de alunos por sala etc.), ainda haja falta de escolas em regiōes específicas. Isto pode ocorrer porque a oferta excedente não se encontra, necessariamente, onde se encontra a criança excluída. Um exemplo típico disso é observável na Região Metropolitana de São Paulo. Apesar do conjunto de vagas ser suficiente para atender toda a demanda, nas regiōes centrais "sobram" vagas e nas periféricas "faltam", sendo comum, ainda, escolas com três turnos diários.

Da mesma forma, devido à regularização do fluxo, compreende-se a redução da matrícula total a partir de 2000. Ao contrário de representar "menos acesso à educação", ela representa mais, pois significa que aqueles que estavam com defasagem série-idade no ensino fundamental progrediram para etapas posteriores. A matrícula, ainda que não linearmente, converge para a população na faixa etária. Vale dizer, mantida a tendência, a matrícula total no ensino fundamental continuará caindo até patamares próximos de 28 milhões, que é a população de 7 a 14 anos. Com a incorporação da coorte etária de 6 anos ao ensino fundamental, estes números tendem a se estabilizar aproximadamente em 31 milhões de matriculas.

Por esses dados, observa-se que, ao longo dos últimos anos, acentuou-se o processo de incorporação ao sistema de ensino da grande maioria da população, praticamente superando a causa histórica e mais significativa de exclusão: a falta de escolas. 
Ainda que ocorrendo concomitantemente a esta, à medida que a exclusão por falta de escola diminuiu, visibilizou-se uma outra, a que ocorre no interior do sistema de ensino. A primeira manifestação dessa forma de exclusão evidenciou-se na existência de barreiras organizacionais ao progresso do aluno. $\mathrm{O}$ exemplo mais típico disso é o antigo exame de admissão ao ginásio. $\mathrm{O}$ efeito desse instituto, que funcionou, historicamente, como um verdadeiro "gargalo", foi que, desde os anos de 1930, ampliou-se o acesso ao ensino primário (Beisiegel, 1964, 1986), mas o acesso ao ginásio permaneceu, por décadas, restrito. Acrescente-se que, a partir da Constituição de 1934 , o ensino primário passa a ser direito e dever de todos. ${ }^{11}$

Ainda que limitado pela oferta insuficiente, após o ensino primário, o sistema selecionava fortemente, impedindo a progressão, pela falta de escolas e pelo estabelecimento da barreira meritocrática, consubstanciada no exame de admissão ao ginásio, que "legitimava" a exclusão.

A ausência de escola vai ser enfrentada por demandas populares pela expansão do sistema (Sposito, 1984). A supressão da barreira do exame de admissão só seria superada ao final dos anos de 1960, quando se amplia a escolarização obrigatória para oito anos, deixando de ter sentido um obstáculo formal ao progresso de todos. Sua manutenção seria a negação da própria ampliação da escolaridade obrigatória como direito de todos.

O impacto do fim do exame de admissão foi visível e imediato. Rapidamente, ampliam-se as taxas de acesso ao antigo ginásio, agora reunido ao primário em um primeiro grau de oito anos. Isso se evidencia, em linhas gerais, no exposto na Tabela 2. Ao se ampliar o acesso, visibiliza-se outra exclusão, a que se produz no interior do sistema escolar. Passávamos da exclusão da escola para a exclusão na escola. Os alunos chegavam ao sistema de ensino, lá permanecendo alguns anos, mas não concluíam qualquer etapa do seu processo de formação, em virtude de múltiplas reprovações seguidas de abandono.

Este fenômeno não é novo (Oliveira, 1992). Tomando a matrícula na primeira série do ensino fundamental, de três gerações de estudantes que ingressaram no sistema em períodos diferentes, o percentual das crianças que logravam chegar ao primeiro ano do curso superior era de 2,4; 4,8 e 6,7\%, respectivamente, para as gerações escolares de 19291940, 1960-1971 e 1977-1988, o que evidenciava uma grande 
Da universalização do ensino fundamental ao desafio da qualidade...

seletividade no interior do sistema escolar ${ }^{12}$ em momentos bastante diferentes.

Sua identificação remonta aos primórdios da organização mais sólida dos sistemas de ensino, na Primeira República. Os trabalhos pioneiros de Almeida Júnior e Oscar Thompson, propondo o fim da reprovação, no final dos anos de 1910, já evidenciam a percepção dessa forma de exclusão. Esses autores sugeriam o fim da reprovação como forma de "criar" vagas para os novos contingentes que ingressariam no sistema de ensino e que, pelas reprovações, se viam impedidos de fazê-lo (Arelaro, 1988). É interessante observar que, nesse caso, a questão da reprovação se articulava com a falta de vagas para excluir. Entretanto, apenas com a ampliação do acesso é que se vai observar com crescente preocupação os processos de "produção do fracasso escolar" e a extensão da chamada "pedagogia da repetência” (Patto, 1990; Ribeiro, 1991).

Ao final dos anos de 1970, a reprovação, seguida da evasão, já era identificada como problema capital de nossa educação. Nos anos seguintes, será enfrentada com políticas sistêmicas visando reduzi-la, cuja expressão mais acabada é a sua proibição em determinadas etapas,

\section{Gráfico 1}

(Matrícula no ensino fundamental regular - Brasil)

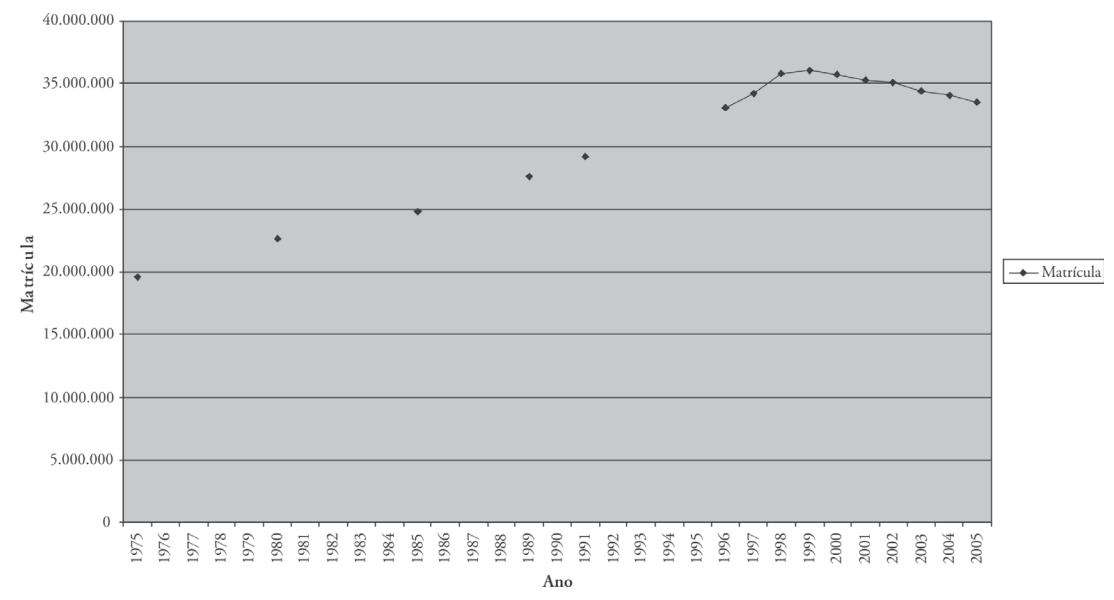

Fonte: Elaborado pelo autor a partir dos dados da Tabela 1. 
por meio das políticas de ciclos, implantadas em vários sistemas de ensino. Entretanto, mesmo em sistemas que não a proibiram administrativamente, generalizaram-se programas de combate à reprovação. A meta era "regularizar o fluxo".

Antes de prosseguir nessa linha de raciocínio é interessante chamar a atenção para outro aspecto da Tabela 2. Observe-se a seguir o gráfico dos dados ali apresentados.

Até atingir seu pico, em 1999, a evolução da matrícula inicial praticamente não foi alterada, sofrendo pequena variação ascendente após 1995. Isso significa que a ação de expansão da matrícula constitui processo sistêmico de longo prazo. A ação dos governos tem relativamente pouco impacto em sua dinâmica. Encontramos aqui outra evidência do argumento de fundo que estamos construindo. A ação dos diferentes governos nesse particular é condicionada por um processo social mais amplo e sob o qual eles têm capacidade limitada de agir, positiva ou negativamente.

O processo de regularização do fluxo no ensino fundamental pode ser bem observado ao analisar-se a matrícula em cada um dos seus ciclos, conforme a Tabela 3. A concentração percentual de matrículas nas

\section{Tabela 3}

(Ensino fundamental - Matrícula inicial de $1^{\mathrm{a}}$ a $4^{\mathrm{a}}$ e de $5^{\mathrm{a}}$ a $8^{\mathrm{a}}$ séries. Brasil: 1975-2005)

\begin{tabular}{|c|c|c|c|c|c|}
\hline \multirow{2}{*}{ Ano } & \multicolumn{6}{|c|}{ Matrícula por série } \\
\cline { 2 - 7 } & Total & $\mathbf{1}^{\mathbf{a}} \mathbf{a} \mathbf{4}^{\mathbf{a}}$ série & $\%$ & $5^{\mathbf{a}} \mathbf{a} \mathbf{8}^{\mathbf{a}}$ série & $\%$ \\
\hline 1975 & 19.549 .249 & 13.924 .849 & 71,2 & 5.624 .400 & 28,8 \\
\hline 1980 & 22.598 .254 & 16.089 .731 & 71,2 & 6.508 .523 & 28,8 \\
\hline 1985 & 24.769 .359 & 17.347 .314 & 70,0 & 7.422 .045 & 30,0 \\
\hline 1989 & 27.557 .542 & 18.851 .075 & 68,4 & 8.706 .467 & 31,6 \\
\hline 1993 & 30.548 .879 & 19.783 .273 & 64,8 & 10.765 .606 & 35,2 \\
\hline 1996 & 33.131 .270 & 20.027 .240 & 60,4 & 13.104 .030 & 39,6 \\
\hline 1999 & 36.170 .643 & 21.013 .899 & 58,1 & 15.156 .744 & 41,9 \\
\hline 2000 & 35.717 .948 & 20.201 .506 & 56,5 & 15.516 .442 & 43,5 \\
\hline 2003 & 34.438 .749 & 18.919 .122 & 54,9 & 15.519 .627 & 45,1 \\
\hline 2005 & 33.534 .561 & 18.465 .505 & 55,1 & 15.069 .056 & 44,9 \\
\hline
\end{tabular}


Da universalização do ensino fundamental ao desafio da qualidade...

primeiras séries diminui e, em contraposição, o número de matriculados nas últimas aumenta. Num contexto de expansão da matrícula total, os alunos progridem mais ao longo do ensino fundamental do que o faziam há alguns anos.

Os dados evidenciam grande concentração de matrículas nas quatro primeiras séries em meados dos anos de 1970. Isto se deve ao fato destas séries apresentarem, historicamente, os maiores índices de reprovação e constituírem aquela etapa em que se admitia a presença das camadas populares. Entretanto, no período considerado, o percentual de matrícula das quatro séries iniciais tem diminuído constantemente, com exceção de 1979 para 1980, enquanto que nas quatro últimas séries tem aumentado, ainda que lentamente. Do início da década de 1980 até 2003, o percentual de matrícula nas quatro primeiras séries cai de $71,2 \%$ para $54,9 \%$, enquanto que o percentual das quatro últimas passa de $28,8 \%$ para $45,4 \%$, aproximando-se de $50 \%$ em ambos os sentidos, o que indicaria um fluxo regular. Observa-se pequena variação para cima em 2004 e 2005.

Isso revela uma importante tendência, resultante da implementação generalizada de processos para regularização do fluxo ao longo destas décadas: a redução gradativa da exclusão no ensino fundamental por múltiplas reprovações ou evasão. Apesar dos números absolutos de matrícula nas séries iniciais revelarem a existência de um grande número de crianças fora da faixa etária esperada (7 a 10 anos), o crescimento do número de matriculados nas séries finais indica maior permanência e sucesso.

A Lei n. 9.394/96 contribuiu para esta tendência, ao explicitar a possibilidade de adoção de mecanismos como os ciclos, a aceleração de estudos, a recuperação paralela e a reclassificação, entre outras medidas indicadas nos artigos 23, 24 e 32, parágrafos $1^{\circ}$ e $2^{\circ}$. Tais medidas não eram proibidas pela legislação anterior, mas raramente implementadas pelos sistemas de ensino (Arelaro, 1988).

$\mathrm{Na}$ Tabela 4 pode-se verificar esse processo série a série. Tanto em valores absolutos quanto em relativos, a primeira série, historicamente, concentrou o maior número de matrículas. Significa dizer, também, que esta série concentrou a maior parte das reprovações. ${ }^{13}$ A Tabela 4 mostra que o percentual de matrículas, em 2005, é mais alto para a primeira série: $14,4 \%$, apesar da diminuição verificada no período, 
pois para esta mesma série, durante a década de 1970, este número girava em torno de $30 \%$.

Concebendo-se um fluxo absolutamente homogêneo, a participação percentual ideal de cada série seria de 12,5\% (100\% de matrículas/ oito séries). Comparando estes dados com os da Tabela 4, observa-se que há uma tendência de convergência em torno deste percentual. As segunda, terceira, quarta, quinta e sexta séries já se aproximam bastante deste número ideal, enquanto que a sétima e a oitava encontram-se, neste momento, mais distantes desse ponto.

\section{Tabela 4}

(Ensino fundamental - Distribuição percentual da matrícula por série. Brasil: 1975-2005)

\begin{tabular}{|c|c|c|c|c|c|c|c|c|}
\hline \multirow{2}{*}{ Ano } & \multicolumn{8}{|c|}{ Matrícula por série } \\
\cline { 2 - 9 } & $\begin{array}{c}\mathbf{1}^{\mathrm{a}} \\
\text { série }\end{array}$ & $\begin{array}{c}\mathbf{2}^{\mathrm{a}} \\
\text { série }\end{array}$ & $\begin{array}{c}\mathbf{3}^{\mathrm{a}} \\
\text { série }\end{array}$ & $\begin{array}{c}\mathbf{4}^{\mathrm{a}} \\
\text { série }\end{array}$ & $\begin{array}{c}\mathbf{5}^{\mathrm{a}} \\
\text { série }\end{array}$ & $\begin{array}{c}\mathbf{6}^{\mathrm{a}} \\
\text { série }\end{array}$ & $\begin{array}{c}7^{\mathrm{a}} \\
\text { série }\end{array}$ & $\begin{array}{c}\mathbf{8}^{\mathrm{a}} \\
\text { série }\end{array}$ \\
\hline 1975 & 29,3 & 16,0 & 12,9 & 10,9 & 9,8 & 7,6 & 6,4 & 5,0 \\
\hline 1980 & 31,0 & 16,4 & 13,3 & 10,5 & 10,1 & 7,6 & 6,2 & 5,0 \\
\hline 1985 & 27,2 & 18,1 & 13,6 & 11,0 & 11,1 & 7,9 & 6,2 & 4,8 \\
\hline 1989 & 23,1 & 16,1 & 14,0 & 11,4 & 12,0 & 8,4 & 6,3 & 4,9 \\
\hline 1991 & 20,7 & 15,8 & 14,3 & 11,9 & 12,7 & 9,0 & 6,8 & 5,2 \\
\hline 1996 & 19,3 & 15,7 & 13,6 & 11,9 & 13,3 & 10,5 & 8,7 & 7,1 \\
\hline 2000 & 17,0 & 14,2 & 13,4 & 12,0 & 13,3 & 11,3 & 10,0 & 8,8 \\
\hline 2005 & 14,4 & 13,2 & 12,5 & 12,4 & 13,5 & 11,6 & 10,4 & 9,5 \\
\hline
\end{tabular}

Pode-se dizer que a pirâmide educacional entre 1975 e 1980 está bem estabelecida, ou seja, há um maior número de matrículas na primeira série e um número absoluto ou percentual sempre decrescente até a oitava série. Entretanto, a partir de 1984, o número absoluto e percentual de matrículas na quinta série é sempre superior ao da quarta, indicando que, além do atendimento aos alunos egressos da série anterior, pode ter havido a absorção de novos segmentos populacionais 
Da universalização do ensino fundamental ao desafio da qualidade...

na quinta série, especialmente nos últimos anos. Outra possibilidade é que esta série concentre número maior de reprovações que a série anterior. De toda forma, a "distância" entre esse percentual e os $12,5 \%$ do fluxo regular, ao longo de todo o período, diminuiu.

Uma das críticas que tem sido levantada contra este processo é que tal "regularização" do fluxo estaria ocorrendo em detrimento da qualidade de ensino. Sem entrar no mérito da discussão acerca do significado que o termo "qualidade" adquire nesse tipo de discurso, o que está se observando aqui é que um dos tradicionais mecanismos de exclusão da escola, reprovação seguida de evasão, está sendo minimizado. Esse processo coloca o sistema escolar, talvez pela primeira vez em nossa história educacional, ante o desafio de assumir a responsabilidade pelo aprendizado de todas as crianças e jovens, responsabilizando-se por seu sucesso ou fracasso. A estratégia de "culpabilização" da vítima perde força (Patto, 1990; Kozol, 1992).

Observe-se agora como se dá esse movimento, considerando-se as diferentes regiōes. Na Tabela 5 são apresentados os números absolutos de matrícula no período de 1975-2005 e, na Tabela 6, os números em termos relativos, adotando-se o índice 100 para 1975.

\section{Tabela 5}

(Matrícula no ensino fundamental por regiāo - 1975-2005)

\begin{tabular}{|c|c|c|c|c|c|c|}
\hline Região/ano & Norte & Nordeste & Sudeste & Sul & Centro-Oeste & Brasil \\
\hline 1975 & 780.570 & 5.216 .543 & 8.664 .782 & 3.590 .575 & 1.296 .779 & 19.549 .249 \\
\hline 1980 & 1.136 .547 & 6.756 .430 & 9.521 .822 & 3.583 .778 & 1.599 .677 & 22.598 .254 \\
\hline 1985 & 1.678 .731 & 7.438 .889 & 10.057 .634 & 3.655 .869 & 1.938 .236 & 24.769 .359 \\
\hline 1989 & 2.155 .068 & 8.105 .453 & 11.300 .227 & 3.992 .351 & 2.004 .443 & 27.557 .542 \\
\hline 1991 & 2.246 .339 & 8.650 .474 & 11.965 .480 & 4.201 .369 & 2.140 .062 & 29.203 .724 \\
\hline 1996 & 2.820 .531 & 10.475 .469 & 12.958 .674 & 4.475 .774 & 2.400 .822 & 33.131 .270 \\
\hline 2000 & 3.273 .693 & 12.509 .126 & 12.936 .313 & 4.416 .528 & 2.582 .288 & 35.717 .948 \\
\hline 2005 & 3.348 .370 & 11.189 .835 & 12.324 .167 & 4.227 .181 & 2.445 .008 & 33.534 .561 \\
\hline
\end{tabular}




\section{Tabela 6}

(Crescimento da matrícula no ensino fundamental por região - 1975-2005

$[1975=100])$

\begin{tabular}{|c|c|c|c|c|c|c|}
\hline Região/ano & Norte & Nordeste & Sudeste & Sul & Centro-Oeste & Brasil \\
\hline 1975 & 100,0 & 100,0 & 100,0 & 100,0 & 100,0 & 100,0 \\
\hline 1980 & 145,6 & 129,5 & 109,9 & 99,8 & 123,4 & 115,6 \\
\hline 1985 & 215,1 & 142,6 & 116,1 & 101,8 & 149,5 & 126,7 \\
\hline 1989 & 276,1 & 155,4 & 130,4 & 111,2 & 154,6 & 141,0 \\
\hline 1991 & 287,8 & 165,8 & 138,1 & 117,0 & 165,0 & 149,4 \\
\hline 1996 & 361,3 & 200,8 & 149,6 & 124,7 & 185,1 & 169,5 \\
\hline 2000 & 419,4 & 239,8 & 149,3 & 123,0 & 199,1 & 182,7 \\
\hline 2005 & 429,0 & 214,5 & 142,2 & 117,7 & 188,5 & 171,5 \\
\hline
\end{tabular}

O maior crescimento relativo, no período, foi observado na regiāo Norte, seguido pelo Nordeste e Centro-Oeste, com taxas superiores às verificadas em nível nacional. As menores, no Sul (apenas 17\%) e no Sudeste $(42 \%)$. Isto não significa que tenha havido menor atendimento nessas regiōes. Na verdade, como a defasagem nas demais era maior, o impacto percentual na ampliação foi maior. Ao se expandir o sistema, proporcionalmente, foram incorporados mais alunos nas regióes que se encontravam mais defasadas. Do ponto de vista da ampliação do acesso, nas regióes Sul e Sudeste o impacto do processo foi menor do que nas demais, nesse período, porque esta expansão aconteceu anteriormente. $\mathrm{Na}$ região Sul, o percentual máximo foi atingido em 1997 e, a partir daí, começou a decrescer. Nas demais, o ápice foi atingido em 1999, nas regiões Sudeste e Centro-Oeste, no Nordeste em 2000 e na região Norte, em 2005, o que não significa que não continue a crescer, ainda, nos próximos anos, até que o fluxo se regularize; vale dizer, a matrícula total comece a diminuir e tenda a convergir para a população na faixa etária, realizando-se processo semelhante ao já observado no país como um todo. Dadas as diferenciações regionais, isso ocorre em momentos distintos.

Tome-se como exemplo as regiōes com índices extremos. Na Tabela 7 , são apresentados os números relativos $(1999=100)$ para a região Norte, por estado, retratando-se a matrícula da quinta a oitava 
Da universalização do ensino fundamental ao desafio da qualidade...

séries, onde o acesso se dá mais tarde. Observe-se que há grande diferenciação interna, mas o processo geral é o mesmo. Em 1991, segundo o EDUDATA-Brasil do INEP, a população de 11 a 14 anos, na região, era de 1.077.617 habitantes e, em 2000, de 1.242.656. Isso significa que o sistema só adquiriu a capacidade de atender toda a população na faixa etária a partir de 2005, quando a matrícula total na região atingiu 1.264.299. Assim sendo, é possível que continue a subir ainda mais um pouco, até iniciar o processo de descenso.

\section{Tabela 7}

(Região Norte - Matrícula 5a a 8a séries por estado: 1999-2005 [1999=100])

\begin{tabular}{|c|c|c|c|c|c|c|c|c|}
\hline Ano & Total & Rondônia & Acre & Amazonas & Roraima & Pará & Amapá & Tocantins \\
\hline 1999 & 100,0 & 100,0 & 100,0 & 100,0 & 100,0 & 100,0 & 100,0 & 100,0 \\
\hline 2000 & 99,4 & 101,0 & 100,3 & 101,7 & 100,3 & 99,5 & 97,0 & 93,6 \\
\hline 2001 & 99,4 & 100,0 & 101,2 & 107,2 & 93,6 & 99,7 & 99,0 & 83,5 \\
\hline 2002 & 100,8 & 99,9 & 103,7 & 112,1 & 95,8 & 100,5 & 102,7 & 81,6 \\
\hline 2003 & 100,7 & 99,3 & 102,6 & 112,7 & 95,5 & 100,6 & 104,7 & 79,6 \\
\hline 2004 & 101,6 & 100,3 & 105,0 & 118,0 & 98,5 & 100,0 & 106,8 & 77,0 \\
\hline 2005 & 101,7 & 98,6 & 106,3 & 119,8 & 103,6 & 99,5 & 108,3 & 76,3 \\
\hline
\end{tabular}

Enquanto que, no Tocantins, o ápice de expansão da matrícula ocorreu em 1999 (ou anteriormente), reduzindo-se constantemente desde então, no Amazonas, a expansão mantém-se até o presente, estando os demais aproximadamente estabilizados. É interessante lembrar que Tocantins foi desmembrado de Goiás, estando mais inserido na lógica de expansão da região Centro-Oeste, que tem perfil semelhante ao da média nacional.

O mesmo ocorre nas regióes Sul (Tabela 8) e Sudeste (Tabela 9). No caso da segunda, o ápice provavelmente foi atingido anteriormente, exceto para Santa Catarina, onde este ponto é atingido em 2000 e, em ambos, a população na faixa etária 11-14 anos é menor que a matrícula no período abrangido pela tabela. 


\section{Tabela 8}

(Região Sul - Matrícula na 5a a 8a séries por estado: 1999-2005 [1999=100])

\begin{tabular}{|c|c|c|c|c|}
\hline Ano & Total & Paraná & Santa Catarina & Rio Grande do Sul \\
\hline 1999 & 100,0 & 100,0 & 100,0 & 100,0 \\
\hline 2000 & 98,8 & 97,7 & 100,2 & 99,0 \\
\hline 2001 & 97,9 & 97,6 & 98,5 & 97,9 \\
\hline 2002 & 97,8 & 97,8 & 98,1 & 97,6 \\
\hline 2003 & 97,2 & 98,1 & 97,4 & 96,2 \\
\hline 2004 & 96,3 & 97,2 & 97,1 & 95,0 \\
\hline 2005 & 94,5 & 95,4 & 96,0 & 92,8 \\
\hline
\end{tabular}

\section{Tabela 9}

(Região Sudeste - Matrícula na 5a a 8a séries por estado: 1999-2005 [1999=100])

\begin{tabular}{|c|c|c|c|c|}
\hline Total & Minas Gerais & Espírito Santo & Rio de Janeiro & São Paulo \\
\hline 100,0 & 100,0 & 100,0 & 100,0 & 100,0 \\
\hline 98,5 & 95,4 & 103,9 & 100,9 & 99,0 \\
\hline 95,0 & 92,4 & 99,1 & 101,2 & 94,1 \\
\hline 93,3 & 93,2 & 98,1 & 101,1 & 90,4 \\
\hline 91,3 & 92,0 & 95,7 & 100,3 & 87,6 \\
\hline 89,8 & 89,7 & 93,2 & 98,4 & 86,8 \\
\hline 89,4 & 87,3 & 91,1 & 98,8 & 87,4 \\
\hline
\end{tabular}

Ainda que com diferenciações quanto à abrangência e ritmo, em termos regionais, estaduais e intra-estaduais, o processo de ampliação do acesso, tanto da população na faixa etária quanto fora dela, é generalizado, o que se observa pela elevação dos patamares de conclusão ao longo dos últimos vinte anos (Tabela 10).

No período, o número de concluintes se aproxima da coorte etária. Ainda que esteja relativamente distante (algo em torno de 20\%), 
Da universalização do ensino fundamental ao desafio da qualidade...

certamente é uma situação qualitativamente diferente da observada em 1983. Gradativamente, vai se ultrapassando a barreira da conclusão do ensino fundamental.

\section{Tabela 10}

(Número de concluintes no ensino fundamental - Brasil: 1983-2004)

\begin{tabular}{|c|c|c|}
\hline Ano & Total & $\mathbf{1 9 8 3 = 1 0 0}$ \\
\hline 1983 & 859.997 & 100,0 \\
\hline 1986 & 906.000 & 105,3 \\
\hline 1990 & 1.062 .707 & 123,6 \\
\hline 1995 & 1.720 .540 & 200,1 \\
\hline 2000 & 2.648 .638 & 308,0 \\
\hline 2004 & 2.462 .319 & 286,3 \\
\hline
\end{tabular}

Outra forma de perceber essa ampliação é observar a taxa de atendimento, que indica o percentual de um grupo etário que está matriculado no sistema escolar, mesmo que não no período considerado ideal. É um indicador de absorção da população neste sistema. A Tabela 11 apresenta as taxas de atendimento para os grupos etários de 7-14 anos e 15-17 anos no período.

Segundo esses dados, no período de 1980 a 2000, o percentual da população de 7 a 14 anos que estava no sistema escolar passa de 80 para $96,4 \%$ e na faixa de 15 a 17 anos, de 49,7 para $83 \%$. Mesmo que essa população, eventualmente, tenha que recuperar certo atraso no processo de escolarização, os percentuais indicam uma situação nova. A principal forma de exclusão já não é a falta de escola, nem a evasão e nem mesmo a não conclusão do ensino fundamental. Ao contrário, o acesso começa a se generalizar, também, para o ensino médio.

Isso faz com que determinadas parcelas da população, pela primeira vez, concluam com sucesso o ensino fundamental. Ainda que o sistema permaneça como excludente, com alta regressividade social etc., o lócus da exclusão não é mais o mesmo. Isso tem profundas conseqüências para o sistema como um todo e para a natureza das contradiçóes em seu interior. 


\section{Tabela 11}

(Taxa de atendimento para as populaçōes de 7-14 anos e 15-17 anos - 1980-2000)

\begin{tabular}{|c|c|c|}
\hline Ano & De 7 a 14 anos & De 15 a 17 anos \\
\hline 1980 & 80.9 & 49.7 \\
\hline 1991 & 89,0 & 62.3 \\
\hline 1994 & 92.7 & 68.7 \\
\hline 1998 & 95.8 & 81.1 \\
\hline 1999 & 97,0 & 84.5 \\
\hline 2000 & 96.4 & 83,0 \\
\hline Ano & De 7 a 14 anos & De 15 a 17 anos \\
\hline 1980 & 80.9 & 49.7 \\
\hline 1991 & 89,0 & 62.3 \\
\hline 1994 & 92.7 & 68.7 \\
\hline 1998 & 95.8 & 81.1 \\
\hline 1999 & 97,0 & 84.5 \\
\hline 2000 & 96.4 & 83,0 \\
\hline
\end{tabular}

A primeira conseqüência importante é que o papel historicamente desempenhado pelo ensino fundamental, de regulador da demanda para as etapas posteriores da escolarização, deixa de existir.

Mariano Enguita, em uma precisa observação sobre o processo de expansão do acesso à escola, chama a atenção para o fato de a escola fundamental ter seu sentido social alterado pela ampliação do acesso. Ao deixar de ser um privilégio para os setores médios, a marca de distinção que a caracterizava se perde.

Presumia-se que o que era ou parecia ser bom para os que até então vinham desfrutando-o com exclusividade também o seria para os demais. Entretanto, a única coisa que com segurança tinha de indiscutivelmente "bom" era a sua exclusividade, e isto foi justamente a primeira coisa que foi perdida. Perdida essa característica, era apenas uma questão de tempo para que os setores recém-incorporados a cada nível de ensino, e inclusive os mesmos que já o freqüentavam antes, se perguntassem sobre se necessariamente tinha este que continuar sendo o que era ou se, pelo contrário, deveria adaptar-se melhor à diversidade de expectativas e interesses de seu público ampliado. (1995, p. 97) 
Da universalização do ensino fundamental ao desafio da qualidade...

Gradual e tardiamente, uma importante barreira para o progresso no interior do sistema escolar foi sendo suprimida. Isso fez com que, por conseqüência, as parcelas da população que não concluíam o ensino fundamental passassem a fazê-lo. Concomitantemente, o prestígio social do diploma dessa etapa vai diminuindo, principalmente pela sua generalização. Resta aos concluintes a alternativa de buscar a continuidade de sua escolarização. Pressionam, então, pela continuidade no sistema, forçando a ampliação do ensino médio.

O fluxo ainda não é perfeitamente regular, mas se aproxima disso. Dessa forma, neste momento, a contradição ou desafio mais importante já não é "garantir acesso, permanência e sucesso - entendido como conclusão - do ensino fundamental", como se defendia há pouco mais de duas décadas. O centro do argumento construído aqui é que esse processo representa uma mudança de qualidade na educação brasileira.

Evidentemente, a desigualdade e a exclusão permanecem. Não é por isso que sequer o ensino fundamental tenha deixado de ser etapa produtora de desigualdade educativa. Além disso, os discriminados de ontem continuam a ser os discriminados de hoje. Mas a desigualdade existente hoje não é mais a mesma e nem ocorre nos mesmos termos da que ocorria no passado. Setores mais pobres reprovam mais, evadem mais, concluem menos, o mesmo ocorre com negros e meninos, mas, mais importante que isso, aprovam mais, permanecem mais e concluem mais do que em qualquer outro momento de nossa história educacional, ainda que permaneçam como os setores mais excluídos. Só que não são excluídos da mesma maneira que no passado! O ponto é que, se não se enfatizar a positividade que a universalização do ensino fundamental representa, não conseguiremos compreender porque os desafios passam a ser outros. Ao se enfatizar a exclusão de sempre, não se tem elementos para perceber que ela já não é a mesma de duas ou três décadas. A primeira conseqüência disso é a notável expansão do ensino médio.

A ampliação do ensino médio

O ensino médio, historicamente reduto de diminuta parcela, conheceu nos anos de 1990 inédito processo de expansão. Observe-se a evolução da matrícula no período 1970-2005 (Tabela 12). O crescimento 
é notável, particularmente na década de 1990, quando se ampliou a matrícula em mais de duas vezes. Enquanto que em 1975 atendia-se pouco menos de dois milhóes de alunos, em 2005 esse número ultrapassa os 9 milhões, permanecendo em torno desse patamar nos últimos dois anos.

\section{Tabela 12}

(Matrícula no ensino médio ${ }^{14}$ - Brasil: 1975-2005)

\begin{tabular}{|c|c|c|}
\hline Ano & Matrícula & $\mathbf{1 9 7 5 = 1 0 0}$ \\
\hline 1970 & 1.119 .000 & 57,8 \\
\hline 1975 & 1.936 .000 & 100,0 \\
\hline 1980 & 2.189 .000 & 113,1 \\
\hline 1990 & 3.500 .000 & 180,8 \\
\hline 1996 & 5.739 .077 & 296,4 \\
\hline 2000 & 8.192 .948 & 423,2 \\
\hline 2005 & 9.031 .302 & 466,5 \\
\hline
\end{tabular}

Esses dados são apresentados no Gráfico 2, a seguir, onde se pode verificar que, diferentemente do ensino fundamental, onde o crescimento foi mais constante e homogêneo, no caso do ensino médio, há um "salto", observado na segunda metade dos anos de 1970.

Confrontando-se esses dados com a população na faixa etária de 15 a 17 anos, em dois momentos, pode-se verificar que a expansão supera, em muito, o crescimento da população na faixa etária, que cresce em ritmo muito mais lento. Em 1991, essa população correspondia a 9.275.706 e, em 2000, a 10.702.499, um crescimento de $15 \%$ no período. A Tabela 13 apresenta as TML e TMB no período 1980-2000 e permite que se observe a intensidade da expansão realizada.

Ainda que a pretendida universalização do acesso esteja relativamente distante, a capacidade instalada se aproxima com rapidez de ter condições de atender a toda a população na faixa etária. Se levarmos em consideração que as taxas de conclusão do ensino fundamental não devem crescer significativamente nos próximos anos, posto que é possível, em breve, atender toda a coorte etária e o fluxo está se regularizando, é 
Da universalização do ensino fundamental ao desafio da qualidade...

\section{Gráfico 2}

(Matrícula no ensino médio - Brasil)

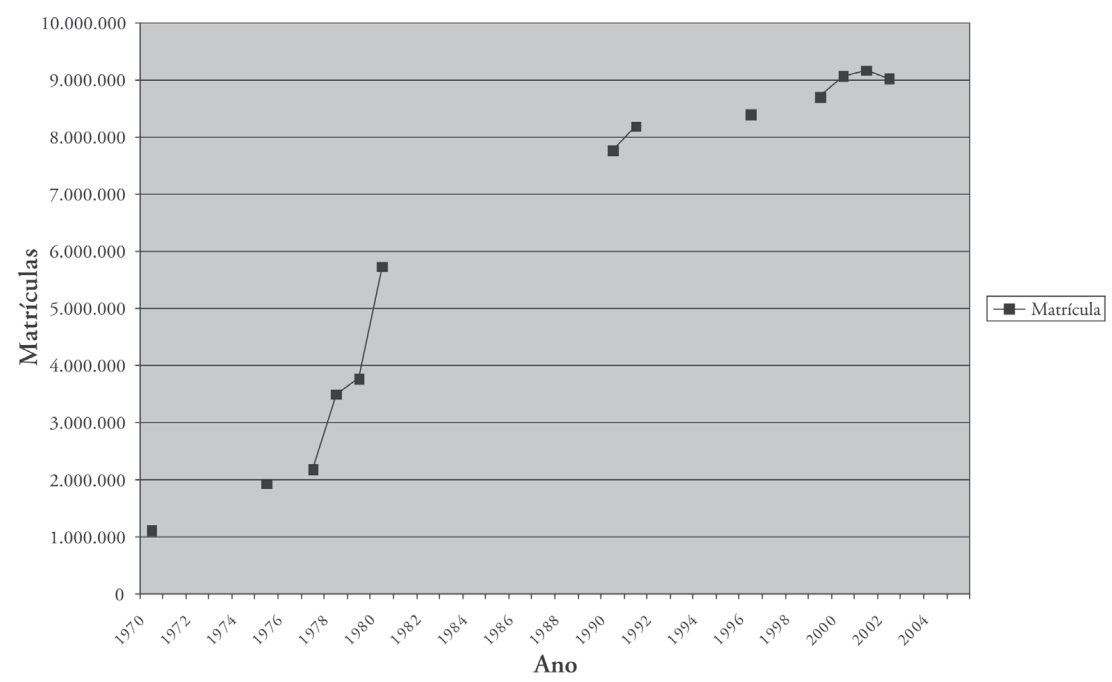

razoável supor-se que o esforço de ampliação não necessite ser muito grande para atender a todos. Evidentemente, dada a já mencionada diferenciação nacional, em algumas regiōes a expansão representará mais esforço, pois os déficits históricos são acentuados e já se convive com crônica falta de recursos e de capacidade instalada. Este é o caso particularmente das regióes Norte e Nordeste.

\section{Tabela 13}

(TML e TMB no ensino médio - Brasil: 1980-2000)

\begin{tabular}{|l|l|l|}
\hline & TML & TMB \\
\hline 1980 & 14.3 & 33.3 \\
\hline 1991 & 17.6 & 40.7 \\
\hline 1994 & 20.8 & 47.6 \\
\hline 2000 & 33.3 & 76.6 \\
\hline
\end{tabular}


Por esses dados, observa-se que, em 1991, a taxa de matrícula bruta era de $40,7 \%$ e em 2000 , de $76,6 \%$. No ano de 1980 , a taxa de escolarização líquida era de $14,3 \%$ e, em 2000 , de $33,3 \%$. A capacidade instalada, indicada pela taxa de matrícula bruta, cresceu significativamente, mais que duplicando o percentual no período de 20 anos. ${ }^{15} \mathrm{~A}$ matrícula líquida ainda está distante de 100\%, mas crescendo em ritmo acelerado.

Se observarmos a conclusão do ensino médio, apresentando dados a partir de 1998 (Tabela 14), pode-se verificar que, ao longo desta década, os índices estão relativamente estabilizados em pouco mais de $50 \%$ da coorte etária. Isso evidencia o longo caminho ainda necessário para que se universalize a conclusão dessa etapa da educação básica.

Tabela 14

(Concluintes do ensino médio - Brasil)

\begin{tabular}{|c|c|c|}
\hline Ano & Total & $\mathbf{1 9 9 8}=\mathbf{1 0 0}$ \\
\hline 1.998 & 1.535 .943 & 100,0 \\
\hline 1.999 & 1.786 .827 & 116,3 \\
\hline 2.000 & 1.836 .130 & 119,5 \\
\hline 2.001 & 1.855 .419 & 120,8 \\
\hline 2.002 & 1.884 .874 & 122,7 \\
\hline 2.003 & 1.851 .834 & 120,6 \\
\hline 2.004 & 1.879 .044 & 122,3 \\
\hline
\end{tabular}

Apesar dessa estagnação relativa, o que se pode depreender da comparação dos dados dessa tabela com os de matrícula total é que há um potencial de crescimento significativo, dependente apenas de processos internos ao sistema, relativos principalmente à redução da reprovação e tendencial regularização do fluxo. ${ }^{16}$

\section{Considerações finais}

Vale voltarmos a um ponto que orientou a elaboração do presente texto. Abunda na literatura uma interpretação bastante crítica 
Da universalização do ensino fundamental ao desafio da qualidade...

desse processo de expansão do ensino, enfatizando o que não se alcançou e diminuindo a importância do que se conseguiu. A opção feita neste texto foi chamar a atenção para o que se conseguiu. Não que isso signifique abraçar um otimismo ilusório ou que não se perceba a dimensão das insuficiências e da desigualdade incorporada nessa dinâmica. Entretanto, tomado de um ponto de vista histórico, esse processo reduziu a desigualdade de acesso à educação e não a aumentou, ainda que esta permaneça acentuada. $\mathrm{Na}$ mencionada publicação do IPEA, essa leitura é evidenciada na seguinte passagem:

Um aspecto particularmente importante de nosso sistema educacional é que virtualmente todos entram na escola, mas somente $84 \%$ concluem a 4 a série e $57 \%$ terminam o ensino fundamental. O funil se estreita ainda mais no nível médio, no qual o índice de conclusão é de apenas 37\%, sendo que, entre indivíduos da mesma coorte, apenas $28 \%$ saem com diploma. (IPEA, 2006, p. 129)

Entretanto, se não percebermos que a desigualdade é outra, não estaremos preparados para enfrentá-la adequadamente. Paradoxalmente, mais educação gera demanda por mais educação. Esse é o ponto que procurei assinalar com força neste texto. A universalização do ensino fundamental gerou duas novas demandas populares por acesso à educação. Uma materializada na matrícula no ensino médio e mesmo no ensino superior, implodindo, ironicamente, a vertente de economia de recursos que originou parte das políticas de correção de fluxo. A vertente que prosperou foi a democratizadora, por mais educação, para maior número de pessoas, por mais tempo.

A segunda demanda, propositadamente não mencionada, referese à questão da qualidade. Ainda que não se possa argüir com tranqüilidade que a escola que foi deixada para trás nesse processo, a idílica escola de privilégios de alguns, como menciona Mariano Enguita (1995), tivesse de fato qualidade, no momento em que os setores excluídos anteriormente passam a ingressar e permanecer no sistema, emerge com toda força o desafio de lograr democratizar o conhecimento historicamente acumulado. A superação da exclusão por falta de escola e pelas múltiplas reprovaçôes tende a visibilizar a exclusão gerada pelo não aprendizado ou pelo aprendizado insuficiente, remetendo ao debate acerca da qualidade do ensino. É a qualidade "que oprime o cérebro dos vivos" e ocupa o centro da crítica ao processo presente de 


\title{
expansão, tornando-se a questão central da política educacional refe- rente à educação básica nos próximos anos.
}

\author{
Recebido e aprovado em agosto de 2007.
}

\section{Notas}

1. Segundo informações constantes do Dossiê Nacional 1, de maio de 2006, da Associação Nacional dos Docentes do Ensino Superior (ANDES-SN), nos últimos anos foram ajuizadas açôes contra diversas modalidades de cobrança de cursos em universidades públicas em Goiás, São Paulo, Ceará e Pernambuco, encontrando-se a questão sob análise da justiça, com decisões contraditórias em primeira instância.

2. Dependendo da contagem de população utilizada, em termos nacionais, as taxas de matrícula corresponderiam a 96 ou $97 \%$ da população na coorte etária de 7-14 anos. Mesmo que o que falte atender ainda seja significativo, são números muito menores do que os historicamente verificados.

3. Nos dois anos seguintes, segundo informações do Censo Escolar, esse número teve uma ligeira queda, atingindo em 2004 a 2,46 milhōes de concluintes.

4. Ainda que considerássemos os que concluem a oitava série na idade correta, este número aproxima-se hoje, segundo dados do Censo Escolar de 2005, de 60\%.

5. Por razões explicitadas a seguir, a comparação com 2005 não seria pertinente para aferir o esforço de ampliação do acesso, posto que, a partir de 1999, a matrícula total começa a diminuir.

6. Taxa de matrícula Bruta (TMB) no ensino fundamental é a relação entre o número total de matriculados nesta etapa da educação básica e a população na faixa etária considerada ideal (7 a 14 anos). A Taxa de Matrícula Líquida (TML) é a relação entre os matriculados no ensino fundamental com idades entre 7 e 14 anos e a população nessa faixa etária. A TMB indica a capacidade de atendimento do sistema, enquanto que a TML indica o grau de atendimento dentro da faixa etária ideal. Quanto mais próximas de $100 \%$ forem ambas, simultaneamente, maior a eficiência de um sistema.

7. Todas as tabelas aqui apresentadas foram elaboradas pelo autor com dados do Censo Escolar, obtidos no sítio do INEP (http://www.inep.gov.br).

8. Publicação do IPEA, de 2006, afirma que "Em 2004 apenas três estados do Norte (Pará, Roraima e Acre) apresentavam taxas de escolarização líquida inferiores a 95\% (...) embora acima de 92\%" (IPEA, 2006, p. 135).

9. Os dados utilizados neste texto referem-se à matrícula inicial, alunos matriculados em 31/ 03 do ano respectivo.

10. Este percentual pode diminuir um pouco, quase que inercialmente, mas uma parcela dessa população é composta por setores com pobreza extrema, deficiências e outras causas. Nesse caso, seriam necessárias políticas muito específicas para incorporá-las adequadamente ao sistema educacional.

11. Antes da Lei n. 4.024/61, outra estrutura excludente era a que impossibilitava o aluno migrar de um tipo de escola para outro, como ocorria entre o ensino profissional e o

Educ. Soc., Campinas, vol. 28, n. 100 - Especial, p. 661-690, out. 2007

Disponível em <http://www.cedes.unicamp.br> 
Da universalização do ensino fundamental ao desafio da qualidade...

propedêutico, processo que se tornou conhecido como da dualidade de ensino (cf. Romanelli, 1986).

12. Ainda que esse cálculo trabalhe com a matrícula total, considerando também os alunos fora da faixa etária adequada, dá uma boa idéia da exclusão presente no processo.

13. Apenas para ilustrar, segundo dados do IBGE, em 1980 o percentual de alunos da primeira série reprovados ultrapassava $55 \%$.

14. Os dados referentes ao período de 1970-1990 foram retirados de IPEA (2006) e os seguintes, do sítio do INEP.

15. Na ausência de informação disponível sobre estas taxas para a primeira década deste século, se fizermos uma estimativa, utilizando-se a população de 2000, teríamos uma matrícula bruta de $84 \%$ em 2005 . Esta estimativa não é descabida, posto que a população nessa coorte etária varia pouco em 5 anos.

16. A lógica que sustenta essa afirmação é a seguinte: se temos aproximadamente 9 milhões de matriculados, e estes estivessem perfeitamente distribuídos em três séries, ter-se-ia 3 milhôes por série, o que estaria muito próximo da coorte etária que é de aproximadamente 3,4 milhōes. Para que isso aconteça, basta que se reduza a evasão e repetência no próprio ensino médio, não demandando ampliação da capacidade física, a menos, novamente, das diferenças regionais já mencionadas.

\section{Referências bibliográficas}

ARELARO, L.R.G. A (ex)tensão do ensino básico no Brasil: o avesso de um direito democrático. 1988. Tese (Doutorado) - Faculdade de Educação, Universidade de São Paulo, São Paulo.

BEISIEGEL, C.R. Ação política e expansão da rede escolar. Pesquisa \& Planejamento, São Paulo, n. 8, p. 99-197, 1964.

BEISIEGEL, C.R. Relações entre a quantidade e a qualidade no ensino comum. Revista da Associação Nacional de Educação, Brasília, DF, v. 1, n. 1, p. $41-56,1981$.

BEISIEGEL, C.R. Educação e sociedade no Brasil após 1930. In: Fausto, B. (Org.). História geral da civilização brasileira. 2. ed. São Paulo: DIFEL, 1986. t. 3, v. 4, p. 381-416.

BRASIL. (Constituição 1988). Constituição da República Federativa do Brasil, com as modificaçóes introduzidas pela EC n. 14. Revista dos Tribunais, São Paulo, 1997.

BRASIL. Ministério da Educação. Instituto Nacional de Estudos e Pesquisas Educacionais (INEP). Geografia da educação brasileira. Brasília, DF: MEC/INEP, 2001. 
CUNHA, L.A. A universidade reformada: o golpe de 1964 e a modernização do ensino superior. Rio de Janeiro: Francisco Alves, 1988.

CUNHA, L.A. As agências financeiras internacionais e a reforma brasileira de ensino técnico: a crítica da crítica. In: ZibAS, D.; AgUiAR, M.; BuENo, M.S.S. Ensino médio e a reforma da educação básica. Brasília, DF: Plano, 2002. p. 103-134

DALE, R. Globalização e educação: demonstrando a existência de uma cultura educacional mundial comum ou localizando uma agenda globalmente estruturada para a educação? Educação, Sociedade \& Culturas, Lisboa, n. 16, p. 133-169, 2001.

ENGUITA, M. O discurso da qualidade e a qualidade do discurso. In: Gentili, P.; Silva, T.T. (Org.). Neoliberalismo, qualidade total e educação: visões críticas. 2. ed. Petrópolis: Vozes, 1995. p. 93-110.

INSTITUTO DE PESQUISA ECONOMICA E SOCIAL (IPEA). Brasil: o estado de uma nação. Brasília, DF: IPEA, 2006.

KOZOL, J. Savage inequalities: children in America's schools. New York: Harper, 1992.

MORAES, R.C. As incomparáveis virtudes do mercado: políticas sociais e padrões de atuação do Estado nos marcos do neoliberalismo. In: KRAWCZYK, N.; Campos, M.M.; HadDaD, S. O cenário educacional latino-americano no limiar do Século XXI: reformas em debate. Campinas: Autores Associados, 2000. p. 13-42.

OLIVEIRA, R.P. Política educacional no Brasil: alguns desafios dos anos 90. Revista da Faculdade de Educação da USP, São Paulo, v. 18, n. 1, p. 5-19, jan./jun. 1992.

OLIVEIRA, R.P.; ADRIÃO, T. Organização do ensino no Brasil: níveis e modalidades na Constituição Federal e na LDb. São Paulo: Xamã, 2002.

PATTO, M.H.S. A produção do fracasso escolar: histórias de submissão e rebeldia. São Paulo: T.A. Queiroz, 1990.

RIBEIRO, S.C. A pedagogia da repetência. Estudos Avançados, São Paulo, v. 5, n. 12, p. 7-21, maio/ago. 1991. 
Da universalização do ensino fundamental ao desafio da qualidade...

ROMANELLI, O.O. História da educação no Brasil: 1930-1970. Petrópolis: Vozes, 1986.

SPOSITO, M.P. O povo vai à escola: a luta popular pela expansão do ensino público em São Paulo. São Paulo: Loyola, 1984. 